\title{
Treatment of complex regional pain syndrome using free-flap surgery: a case report
}

\author{
This article was published in the following Dove Press journal: \\ Journal of Pain Research \\ Number of times this article has been viewed
}

\section{Dong-Kyo Seo' \\ Ho-Seong Lee ${ }^{2}$ \\ Joon Pio Hong ${ }^{3}$ \\ Jeong-Ho Seo ${ }^{4}$ \\ Jin Woo Shin ${ }^{5}$}

'Department of Orthopedic Surgery, GangNeung Asan Hospital, College of Medicine, University of Ulsan, GangNeung-si, South Korea; ${ }^{2}$ Department of Orthopedic Surgery, ${ }^{3}$ Department of Plastic Surgery, Asan Medical Center, College of Medicine, University of Ulsan, Seoul, South Korea; ${ }^{4}$ Department of Orthopedic Surgery, Cheil Orthopedic Hospital, Gangnam-gu, Seoul, South Korea; ${ }^{5}$ Department of Anesthesia, Asan Medical Center, College of Medicine, University of Ulsan, Seoul, South Korea
Correspondence: Ho-Seong Lee Department of Orthopedic Surgery, Asan Medical Center, College of Medicine, University of Ulsan, 88, Olympic-ro

43-gil, Songpa-gu, Seoul, 05505,

South Korea

$\mathrm{Tel}+82230103521$

Fax +82 24887877

Email hosng1902@gmail.com

\begin{abstract}
Complex regional pain syndrome is a chronic progressive illness with sensory, autonomic, trophic, and motor abnormalities. Treatment is difficult and controversial. We report the results of free-flap and vein wrapping of the superficial peroneal nerve surgery to treat complex regional pain syndrome.
\end{abstract}

Keywords: foot, ankle, superficial peroneal nerve, vein wrapping

\section{Case presentation}

A 39-year-old man was transferred due to intractable pain and paresthesia in the left ankle and foot. He had a history of multiple ankle sprains and underwent an arthroscopic synovectomy and open repair of the anterior talofibular ligament at the ankle at another hospital. Pain developed after this surgery. He visited the anesthesia pain clinic because of aggravated neuropathic pain.

In our pain clinic, the patient had difficulty walking due to severe pain. There was a $5 \mathrm{~cm}$ surgical scar on the lateral side of his left ankle. The patient reported 10 points on the visual analog scale (VAS). Severe focal tenderness and allodynia were evaluated. The patient complained of tingling sensation along the superficial peroneal nerve, although the range of motion of the ankle was normal. Trophic changes were not observed. Electromyogram/nerve conduction velocity test revealed no definite electrophysiological evidence. A three-phase bone scan revealed diffuse and mildly increased uptake in the blood pool and delayed uptake, which suggested complex regional pain syndrome (CRPS).

Conservative treatment including medication for neuropathic pain and several rounds of sympathetic nerve blocks was unsuccessful. After 10 months, a spinal cord stimulator was inserted, which alleviated the patient's overall pain by about $50 \%$. However, allodynia persisted.

We excised the painful hypertrophic scar and released the adhesive scar tissue around the superficial peroneal nerve. Symptom improved by about $80 \%$ and the patient was very satisfied. However, the symptoms recurred 6 months later. The patient complained of allodynia around the scar area and tingling sensation in the dorsolateral left foot (Figure 1).

After 1 year, we performed a second operation similar to the first operation. An antiadhesive material had also infiltrated the nerve during the operation. Microscopic examination of the adhesive scar tissue revealed the proliferation of nerve twig endings 
with fibrosis. The allodynia slightly decreased after surgery. However, tingling sensation in the forefoot dorsum was not changed (Figure 1). The patient could not sleep well due to the pain. The VAS score was 8-9 points, and the American Orthopedic Foot and Ankle Society score was 24 points. The patient received a consultation from a psychiatrist, who reported no abnormal psychosomatic problems or secondary gains.
In the third surgery, we first widely excised the hypersensitive skin around the scar. The excised skin and subcutaneous tissue measured $13 \times 9 \mathrm{~cm}$. The superficial vein for wrapping the superficial peroneal nerve was harvested from the left inguinal area (Figure 2). The superficial circumflex iliac artery perforator flap was used to cover the skin defect. Microscopic examination of the skin and subcutaneous tissue revealed several nerve

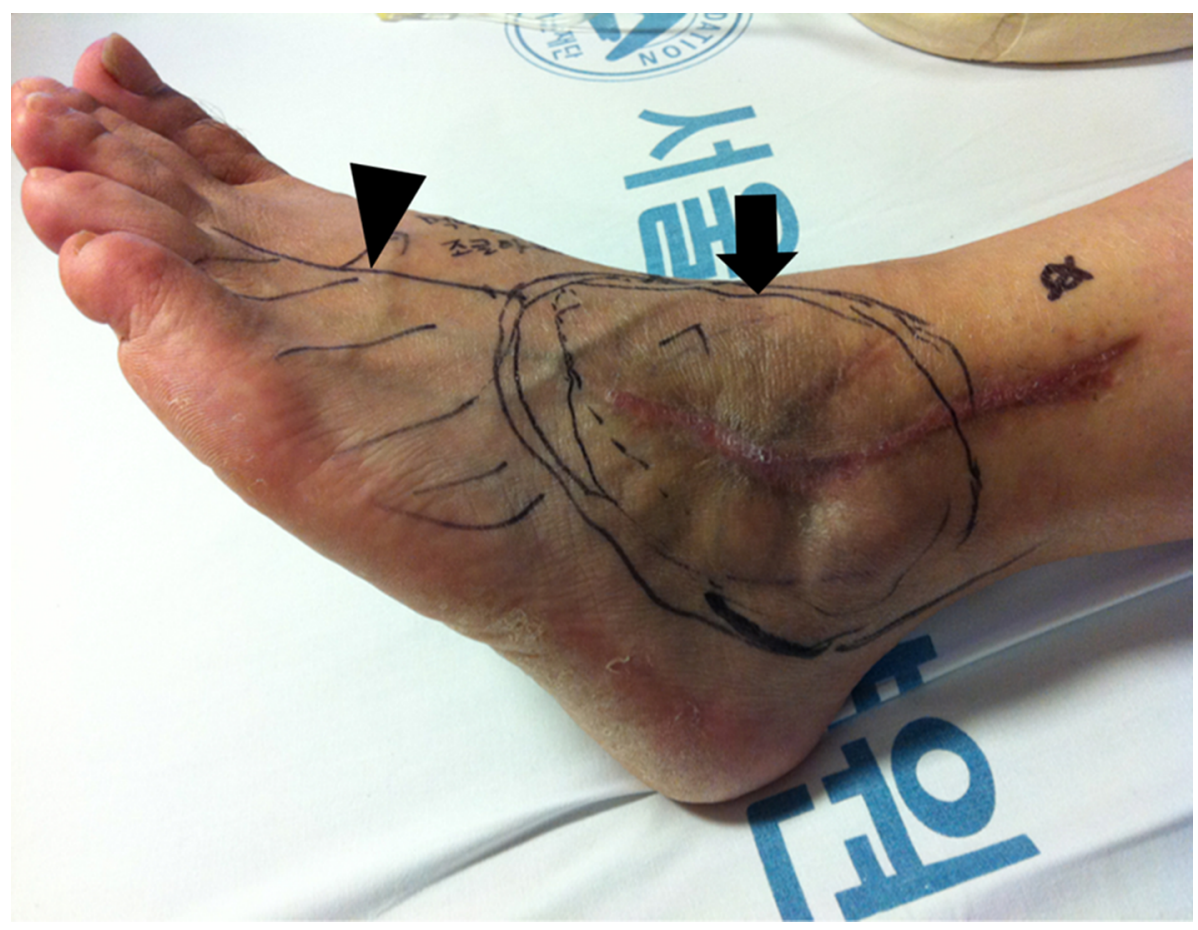

Figure I Allodynia (arrow, circle area) of scar tissue area and hypoesthesia (arrow head, oblique line area) on the dorsolateral side of the foot.

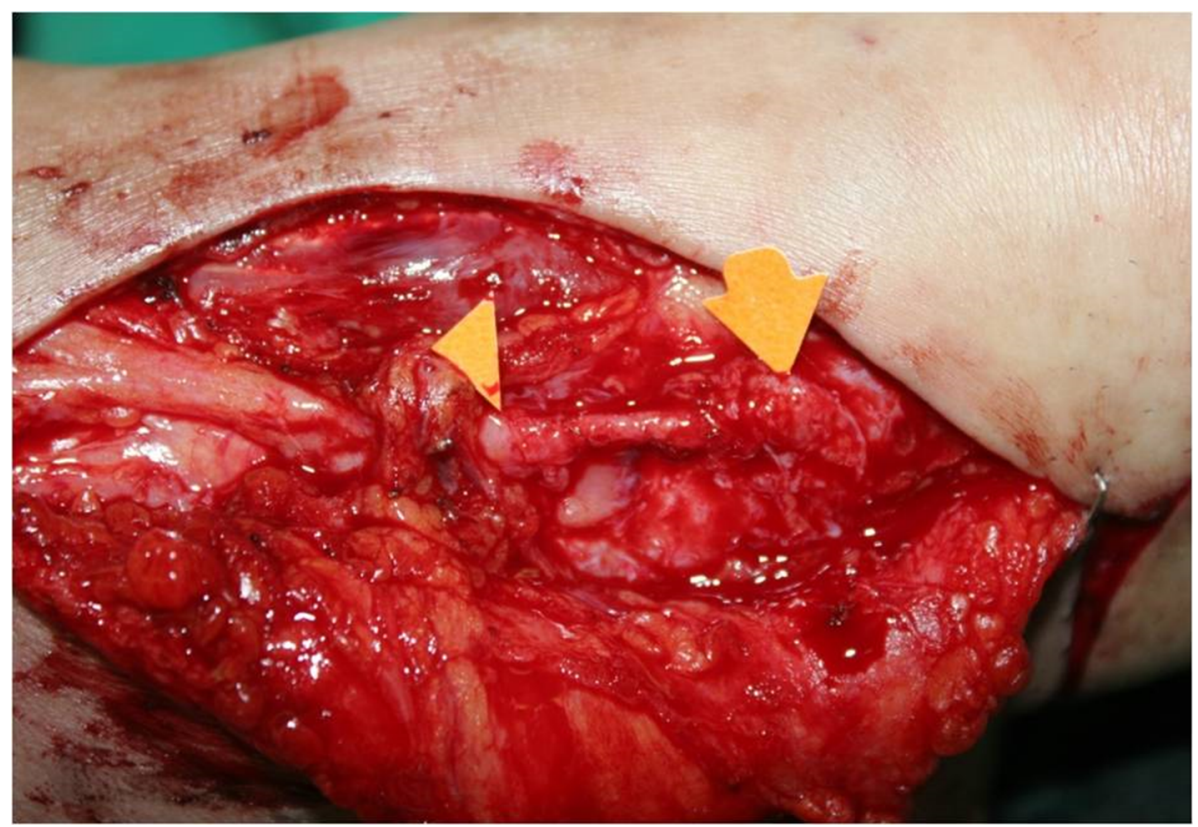

Figure 2 Excision of the hypersensitive painful skin and vein wrapping of superficial peroneal nerve (between arrow head and arrow). 
trunks and a lot of axons. Compared with the contralateral normal skin tissue, the lesion site contained more axons (Figure 3 ).

Allodynia at the scar lesion had almost disappeared, and the VAS score was 2 points. At postoperative 1 month, sensation at the flap site had improved to $60 \%-70 \%$ in comparison with the contralateral normal foot. At 6 months, the sensation was normal and some hair was visible. After 3 years, allodynia disappeared. However, tingling sensation did not disappear on the distant area of the flap site. The patient could tolerate walking and was satisfied with the results of our flap surgery (Figure 4).
This study was approved by Asan Medical Center institutional review board. The patient provided written informed consent for the publication of the case details and any accompanying images.

\section{Discussion and conclusion}

The etiology of CRPS remains unclear, but it can develop as a postoperative complication. Nickisch et $\mathrm{al}^{1}$ reported 2 cases of CRPS that developed in 198 patients who underwent ankle arthroscopy surgery. Appropriate multimodal treatment relieved symptoms within 6 months.

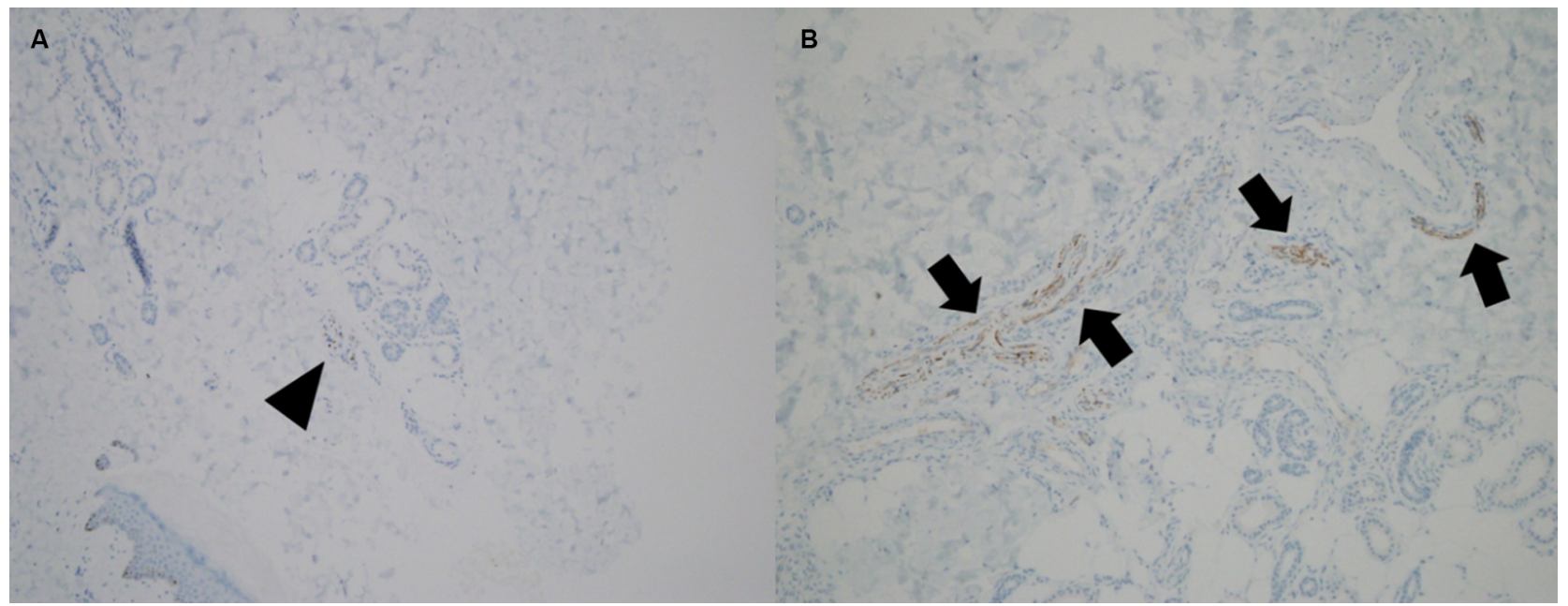

Figure 3 Microscopic findings of immunohistochemistry for neurofilament protein show more axons (arrowhead and arrows) in lesion site (B) than normal skin (A); (hematoxylin and eosin stain 100x).

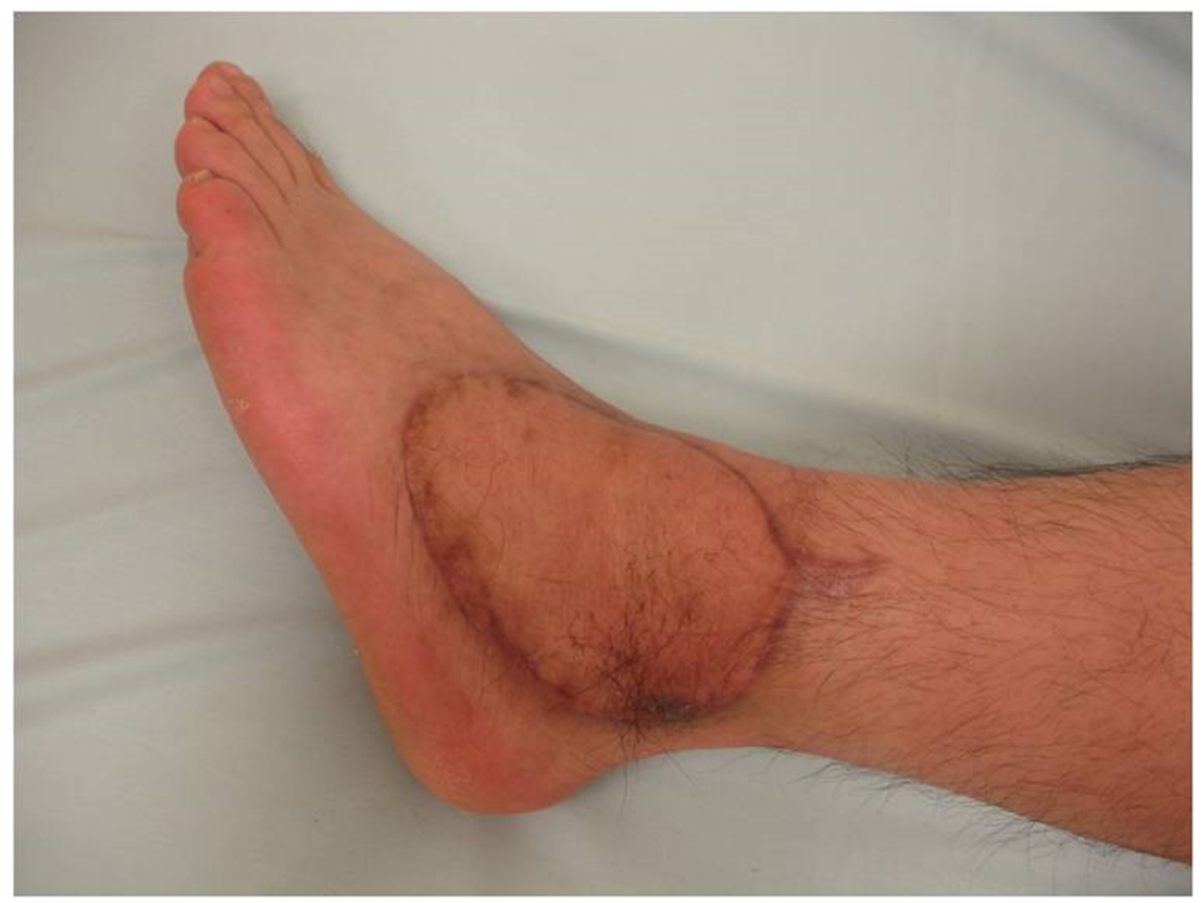

Figure 4 The flap healed well and there was no allodynia I year after flap surgery. 
In our current case, the patient underwent multiple surgeries after his initial arthroscopic surgery. Easley et $\mathrm{al}^{2}$ have reported that CRPS patients undergo an average of 2.5 surgeries (range, 1-7) for the same nerve problem. CRPS is essentially characterized by pain and dysfunction of the sympathetic nervous system. Patients frequently develop hyperesthesia in response to typical mechanical stimuli and extreme sensitivity. Vasomotor autonomic disturbances, like color or temperature changes in the affected limb, often develop. Sudomotor symptoms, such as hyperhidrosis or dryness, may also develop. ${ }^{3}$

However, there is no common standard protocol for treating CRPS. Various opioids and adjuvant medications are used to treat this disorder. ${ }^{4,5}$ Sympathetic nerve block has also been used to reduce CRPS-associated pain as has spinal cord stimulation to treat the chronic pain associated with this condition. ${ }^{6}$ In our current case, the patient did not show improvement following conservative treatment. A pain clinician inserted a spinal cord stimulator. Even though his symptoms improved by $50 \%$, the focal symptoms around the left ankle remained.

After undergoing adhesiolysis operation, the patient's symptoms did not improve, and they worsened further under conservative management for an additional 10 months. We planned to excise the hypersensitive skin and cover the defect with distant healthy tissue to relieve the patient's symptoms. At the 3 years follow-up after flap surgery, intractable allodynia at the flap site disappeared. Lee Dellon et $\mathrm{al}^{7}$ noted that most patients with CRPS type II were referred with a misdiagnosis of CRPS type I. They reported CRPS type II patients can be successfully treated with the appropriate surgical strategy. In our current case, severe symptoms developed around the surgical scar. The pain was not diffuse. The patient was diagnosed with CRPS type II based on these clinical findings.

Vein wrapping of the peripheral nerves was first described by Masear et al. ${ }^{8}$ It can protect nerves by inhibiting tissue adhesion, improving the gliding of the nerve, and decreasing scarring within the nerve trunk. ${ }^{2,9,10}$ However, hypersensitivity did not disappear on the distant area of the flap site in our case. Therefore, the effect of vein wrapping of the nerve was doubtful in this case.

In our challenging case, careful consideration in replacing the hypersensitive skin with healthy tissue by the free-flap surgery is recommended. This can be one of the treatment methods for the CRPS type II.

\section{Author contributions}

All authors contributed toward data analysis, drafting and critically revising the paper, gave final approval of the version to be published, and agree to be accountable for all aspects of the work.

\section{Disclosure}

The authors report no conflicts of interest in this work.

\section{References}

1. Nickisch F, Barg A, Saltzman CL, et al. Postoperative complications of posterior ankle and hindfoot arthroscopy. J Bone Joint Surg Am Vol. 2012;94(5):439-446.

2. Easley ME, Schon LC. Peripheral nerve vein wrapping for intractable lower extremity pain. Foot Ankle Int. 2000;21(6):492-500.

3. Harden RN. Complex regional pain syndrome. Br JAnaesth. 2001;87(1): 99-106.

4. van de Vusse AC, Stomp-van den Berg SG, Kessels AH, Weber WE. Randomised controlled trial of gabapentin in Complex Regional Pain Syndrome type 1 [ISRCTN84121379]. BMC Neurol. 2004;4:13.

5. Collins SL, Moore RA, McQuay HJ, Wiffen P. Antidepressants and anticonvulsants for diabetic neuropathy and postherpetic neuralgia: a quantitative systematic review. J Pain Symptom Manage. 2000;20(6):449-458.

6. Geurts JW, Smits H, Kemler MA, Brunner F, Kessels AG, van Kleef M. Spinal cord stimulation for complex regional pain syndrome type I: a prospective cohort study with long-term follow-up. Neuromodulation. 2013;16(6):523-529.

7. Dellon AL, Andonian E, Rosson GD. CRPS of the upper or lower extremity: surgical treatment outcomes. J Brachial Plex Peripher Nerve Inj. 2009;4:1.

8. Masear VR, Colgin S. The treatment of epineural scarring with allograft vein wrapping. Hand Clin. 1996;12(4):773-779.

9. Kokkalis ZT, Jain S, Sotereanos DG. Vein wrapping at cubital tunnel for ulnar nerve problems. J Shoulder Elbow Surg. 2010;19 (Suppl 2):91-97.

10. Xu J, Varitimidis SE, Fisher KJ, Tomaino MM, Sotereanos DG. The effect of wrapping scarred nerves with autogenous vein graft to treat recurrent chronic nerve compression. J Hand Surg. 2000;25(1):93-103.
Journal of Pain Research

Publish your work in this journal

The Journal of Pain Research is an international, peer reviewed, open access, online journal that welcomes laboratory and clinical findings in the fields of pain research and the prevention and management of pain. Original research, reviews, symposium reports, hypothesis formation and commentaries are all considered for publication.

\section{Dovepress}

The manuscript management system is completely online and includes a very quick and fair peer-review system, which is all easy to use. Visit http://www.dovepress.com/testimonials.php to read real quotes from published authors. 